\title{
Analysis of How Masters' Curriculum Meets the Needs of Masters' Students' Use of Statistics in Research
}

\author{
Joseph Mukuyuni Mubichakani ${ }^{1 *}$, John Simiyu ${ }^{2}$ and Kitainge, M. Kisilu ${ }^{3}$ \\ 1 Lecturer, Science Education Department University of Eldoret \\ 2 Professor, Technology Education Department University of Eldoret \\ 3 Associate Professor, Technology Education Department University of Eldoret
}

\begin{abstract}
Knowledge is valued as a vital asset for progress and prosperity in every sphere of human understanding. Knowledge is attributed with successful innovation in firms. Research has been identified as the main source of knowledge. In Kenya, University students have been accused of doing low quality research. Statistics is important in research, it starts at the planning stage to establish the design and sample size. Studies have pointed to wrong use of statistics as a contributing factor towards low quality research. The purpose of this study was; to determine masters' curriculum meets the needs of masters' students' use of statistics in research, a case of curriculums of universities of western Kenya. Three curriculums from 3 different universities were analyzed. The study established that; general objectives and specific objectives in courses related to statistics adequately covered the requirements for statistics training; the scheduled content for the core courses covered descriptive and inferential statistics; ICT concepts are catered for in the sampled masters' curriculums, however, the courses are too wide to be effectively learned in one semester of 4 months; The study established that lectures, class discussion and students presentations are common methods of instruction across the sampled curriculums. The study established that continuous assessment tests and end of semester sit in exam were the common form of exams administered. In addition in one case there were also term papers and practical in some courses. However the end of semester exam carried more weight of $60 \%$. The study recommended for proper integration of ICT and statistics, increase of statistical courses and use of open book examination.
\end{abstract}

Keywords: Curriculum, Statistics, Research

DOI: $10.7176 / \mathrm{JEP} / 10-21-17$

Publication date:July $31^{\text {st }} 2019$

\section{Introduction}

Knowledge is an important aspect in any given society. Yamamoto (2001) noted that knowledge is valued as a vital asset for progress and prosperity in every sphere of human understanding. Given this importance of knowledge it's prudent that sources of knowledge are identified and protected. Review of documented literature identifies research as a key source of knowledge (Yamamoto (2001); Estabrooks, et al (2005); Assimakopoulos, \& Yan (2006) \& Fletcher \& Harris (2012)). The review also established that universities are the main centres of research and training researchers (Clark (1993); Votruba (1996); Sawyerr (2004); Cloete \& Maassen (2015) \& Mukhwana et al (2016)).

Since research and research training is core in generation of knowledge, it is expected that every university should be striving to perfect it. However, this is not the case for African universities. African universities are still struggling in research (Musiige \& Maassen, 2015). In a count of Web of Science journals, Africa has only 101 journals out of the estimated 14,000 journals worldwide. This translates to $1 \%$ of the journals (Tijssen, 2015). Tijssen also noted that the contribution of University of Nairobi, Kenya, towards published research work was slowing down. Scott (2015) and Mukhwana et al (2016) attributes this to poor quality research in Kenya.

Statistics has been identified as a key concept of research. Statistics in research enables one to; Plan for research; Produce data that provide clear answers to important questions; and Draw trustworthy conclusions based on data (Bishop \& Talbot (2001); Sprent (2003); Zwiers \& Von Storch (2004)). Inadequate understanding of statistics and/or misinterpretation of statistics has been noted to lower the quality of research findings (Murray (1991); Maindonald (1999); Svensson (2001) Bishop and Talbot (2001); Sprent (2003)). Literature review noted two main causes of inadequate understanding of statistics and/or misinterpretation of statistics across Asia, Europe and America. One of the causes identified was research being carried by non statisticians (Glencross \& Binyavanga, 1997); and secondly inadequate training in use of statistics in research (Harraway, et al 2001). The causes of low quality research in Kenya remain unclear but can be hypothesized to be caused by inadequacies in use of statistics as it has been found out in other continents. 
The guiding purpose of this study was; to determine how masters' curriculum meets the needs of masters' students use of statistics in research, a case of universities of western Kenya. The purpose was with a view of incorporating necessary measures into post graduate students use of statistics to develop a knowledgeable workforce in research. In order to accomplish its main purpose the study was broken down to specific objectives that were to be achieved by the end of the study. The following are the specific objectives that guided data collection for the study; determining research and statistical requirements for joining a Masters Class as set by curriculum; determining curriculum objectives in relation to statistics; finding out the statistics content in the curriculum; determining information communication technology content; and finding out the curriculum recommendation for instruction procedures and evaluation.

The study was carried out in 3 universities in western region of Kenya, 2 public and one private. One masters' curriculum in social sciences was sampled from each of the three universities. Content analysis schedule was used to analyze the curriculum.

\section{Literature Review}

The content as scheduled in any given curriculum for training is a key factor in determining the type of trainee the program will graduate. Mukhwana et al (2016) points out that all Universities in Kenya have coursework for masters' students' which include courses on research statistics. A perusal through the published research has little on what specifically is contained in these curriculums. The study, therefore sought to determine the content. However, it was important to lay down an ideal situation of such a curriculum and a benchmark curriculum in order to effectively evaluate the Kenyan masters' curriculum in relation to statistics. The study used a benchmark curriculum of Graduate School for Social Sciences, University of Glasgow.

Scholars as discussed below argue that a good curriculum for research statistics should be broad enough to give an overall picture of statistics. Pearson and Brew (2002) were of the opinion that research statistics training should be very wide and should incorporate the needs for knowledge creation. Pearson and Brew (2002) documented that research training should improve student throughput, be more flexible in an open system and provide students with more support. Mukhwana et al (2016) argued that major scientific discoveries cannot be planned. They noted that discoveries come from giving creative thinkers the freedom to follow new ideas. They indicated that this fact, as most countries agree, underlines the need for research programs and institutional structures that enable innovative approaches and encourage researchers to take risks.

Mukherjee (2001) posts that training of researchers in statistics should equip them to handle their research problems in general and not just one particular problem or project. He notes that training researchers in the use of statistics is a more general task than teaching statistics. Iversen (2001) takes it a notch higher by noting that statistics training to students in liberal arts should go beyond making them researchers. He argues that the purpose is for them to be able to understand the role played by statistics in today's society. These expectations by scholars are very high and it puts pressure on curriculum specialists and trainers.

The benchmark curriculum was noted to have general goals that meet the general requirements of the scholars above. But it is important to note that the core stated in the curriculum are few and do not meet all the general goals, the curriculum, however, has provisions for elective courses to cover for the inadequately met goals. The Kenyan masters' curriculum will be looked at in light of the scholars requirements and benchmarked with this sample curriculum.

Apart from the general overview of statistics, scholars also have an opinion that statistics training should also focus of specifics that are necessary. Wei (2001) argues that the aim of training in statistics should also be to increase the trainee's abilities in their practice. The main abilities he noted that should contain survey designing, data collecting, describing, computing, analyzing and explaining. In order to achieve this purpose, Wei (2001) proposes that these statistical concepts should be put into training materials as well as textbooks. Bishop and Talbot (2001) note that attention should be devoted to strategic issues in statistics such as what technique is most appropriate and how to organize data collection. McDonald (2001) recommended that university courses on quantitative research should include a section on official statistics, and the pros and cons of micro data, e.g. using hierarchical data sets, dealing with missing values and non response, appropriate use of weights, analysis of complex sample design, and confidentiality control.

Jung (2005) notes that because of rapid development in information communication technology (ICT) especially the Internet, traditional initial teacher training as well as in-service continued training institutions worldwide are 
undergoing a rapid change in the structure and content of their training and delivery methods of their courses. These sentiments by Jung had been reported earlier by Bishop and Talbot (2001). They noted that much of statistical education of researchers was focusing on training in specific techniques including the use statistical packages and interpreting results. Starkings (1997) noted that educational establishments need to be updating the curriculum to keep pace with changes in society and the work environment. He argued that technology is and will be a major part of our everyday life.

Given that statistical packages are increasingly being used by researchers, then based on Starkings argument they should be included in statistics training. However, such changes may also come with challenges as noted by Jung (2005) that combining new technologies with effective pedagogy had become a daunting task for both initial teacher training and in-service training institutions. McDonald (2001) recommends practical experience with large and realistic statistical data sets during the training of researcher on how to use statistics. he indicates that it is important for researchers to have the opportunity either to become familiar with software commonly used with large data sets or are trained in the principles of software applications. There were no specific courses on information communication technology in the benchmark curriculum. However, the ICT concepts, specifically statistical software, were well integrated in the courses. It was also noted that the curriculum recommended use of sets of data and real research applications.

A review of the literature revealed that different countries have adopted different ways of training researchers in statistics. Wei (2001) indicated that training researchers in the use of statistics in China is the responsibility of colleges, universities and research institutes. He noted that these institutions are applying different techniques to carry out the training. The most common he identified were; Class teaching, group discussion, field training, TV, broadcasting programs and Internet. Hirotsu (2001) recommends that Japan should extend its training of researchers beyond the university training to training in companies in the actual context that the statistics knowledge will be applied. Some of these may be queer requirements but the study sought to determine the extent to which the statistics training curriculum meets them. A look into the benchmark curriculum showed that the approaches recommended were; lectures, tutorials, class discussion and presentations and workshops. In relation to assessment the benchmark curriculum had a variety of assessment methods appropriate to the subject matter of the different courses. Generally, essays, exercises and project work were required. Each course was assessed on the basis of written course work in the form of a project/lab report and/or a 4000 word essay.

Literature from Africa and specifically Kenya on issues of the curriculum for research training in general and statistics in particular is scanty. Clark (1993) creates doubt on if post graduate training curriculum in developing countries is a well structured document. He states that in any national system the first degree level has historical primacy, predominates numerically and possesses a deep hold on traditional thought and practice. Of most interest he reports that graduate or advanced education in these countries is prone to develop at the margin as an addition of a few more years of unstructured work for a few students. Sawyerr (2004) argues that the extreme weakness of graduate study programs in most African universities is among the most serious of the institutional limitations on research capacity development. Clark and Sawyerr, however, do not present any specifics of the weakness in the research training curriculums.

\section{Findings and Discussion}

\subsection{Research and Statistical Requirements for joining a Masters Class}

In this section the study sought to determine if the masters' curriculum in any way recognizes and requires research and specifically statistics skills and knowledge for one to be enrolled for masters' degree. The study found out that the two requirements for admission were; having a degree in a related field; and the application of university admission regulation. An extract from a sampled curriculum on admission requirements is as presented below.

\section{Curriculum Extract}

"The common University admission regulation for the Masters degree shall apply. The candidates with the following academic qualifications shall be considered for admission; a degree in

Since all the sampled curriculums were referring to university admission regulations, the study followed up to determine what the regulations were. The surveyed universities had several similarities in requirements for joining 
masters program. Universities required that the applicant should have degree in related field with first class or second class upper division. If the applicant had a second class lower division, universities required that, he/she should have at least two years of working experience to qualify for admission. The admission requirements were silent about those applicants who had a pass at their undergraduate level.

Mukhwana et al (2016) noted that minimum admission requirements for post-graduate training in Kenya are similar across all universities. The study based on this point to note that the admissions requirements above are applicable to all universities in Kenya. These requirements do not put into consideration the importance of prior knowledge in statistics and ICT as noted in this study and in other studies including; Starkings and Jerome (2001); Dempster and McCorry (2009) and Estepa and Sánchez (2001) who noted that inadequacy of statistical prior knowledge has an effect on future learning of statistics and its application. Oliver and Towers (2000) noted that inadequacy in ICT is likely to impede learning and progression in courses and programs where use is made of contemporary forms of ICT.

Despite the curriculum not putting into consideration the arguments above it cannot be noted as a major weakness of the curriculum. This is because the students will be trained in how to use statistics. It is, however, important that the trainers are aware of possibilities of having students with no prior knowledge in statistics and ICT. The curriculum and trainers should therefore be very thorough in their training. The study sought to determine if in any way there is a provision to determine the prior knowledge of masters' students. It was established that in the application forms for masters' program applicants are required to fill their previous research experience. This item was a requirement but not a determine factor on whether a student will be enrolled or not.

A perusal through the sampled curriculums did not have any aspects of improving the thorough training that may be required by the admitted students. This conclusion is based on a comparison with benchmark curriculum of Graduate School for Social Sciences, University of Glasgow. The benchmark had mandatory requirements like;

"All students attending the Research Training Programme Induction must already possess basic IT skills. It is their responsibility to ensure they have these skills before the course starts, as computers are used extensively throughout the Research Training Programme. Students who do not possess basic skills in the use of word-processing and the use of e-mail must acquire those skills early in the first semester. Courses that allow students to acquire these computing skills are offered by the University's IT Education Unit."

This will make the students put in effort to learn aspects that they did not have but are important to be trained in statistics. The sampled curriculums are missing these requirements that will push the students to enhance thorough training. The weakness of the sampled curriculums is identified by the study to be; the lack of clauses to ensure the students' are adequately prepared for thorough training in use of statistics in research.

\subsection{Curriculum Objectives in relation to Statistics}

The study was interested in noting the weight given to statistics training for masters' students in sampled universities. The sampled curriculums were analyzed. The study found out that the sampled curriculums had a general objective on research. The study also established that specific courses related to statistics had specific objectives that adequately covered the requirements for statistics training. Extracts from the sampled curriculums are as shown below.

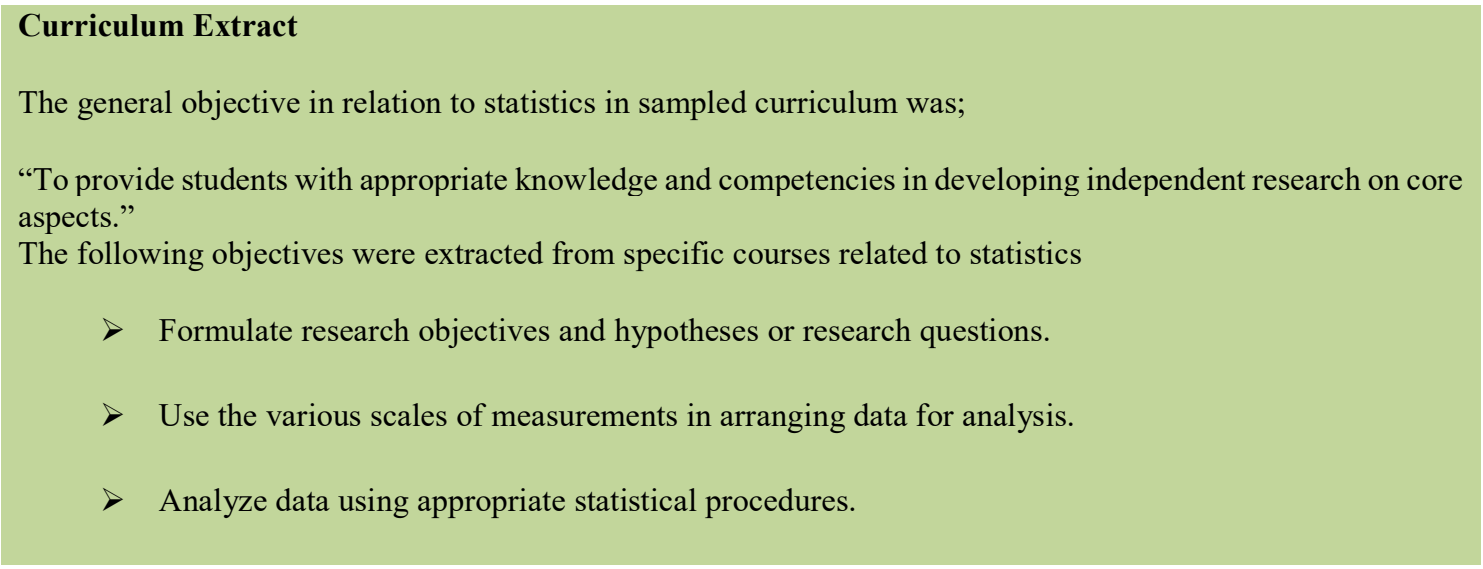


Understand quantitative and qualitative data, parametric and non-parametric tests.

$>$ Understand descriptive and inferential statistics

$>$ Understand Analysis of variance, rational and terms

$>$ Differentiate different types of decisions

$>$ Identify decision analysis software

$>$ Use the various scales of measurements in arranging data for analysis.

$>$ Analyze data using appropriate statistical procedures.

$>$ Understand main aspects of Linear optimization models

$>$ Understand decision making over unbound horizon

$>$ Understand probabilistic dynamic programming

The study determined that the sampled curriculum had adequately covered in its objectives the breadth and depth of research statistics training as recommended by; Pearson and Brew (2002) who recommends that research statistics training should be very wide and should incorporate the needs for knowledge creation; Mukhwana et al (2016) note that the training should broad enough to encourage innovation and creativity; Mukherjee (2001) posts that training should equip researchers to handle their research problems in general. The analyzed curriculums were found to have adequately covered the requirements stated by the scholars above.

The curriculums were, however, found to have less emphasis on research training in general as compared to benchmark curriculum of Graduate School for Social Sciences, University of Glasgow. The benchmark curriculum had a special certificate being given for research trainees who qualify. This certificate was a way of noting the competency of researchers but also made the research training to be taken seriously by trainees. Sabzwari et al (2009) found out that very small proportions of students receive any training in research during their undergraduate studies. This means that the training they get at masters' level is their maiden training in research. Considering that it is the first it is actually prudent that universities in Kenya consider issuing a certificate the same Glasgow university school of social sciences is doing. Despite some short comings the study notes that the sampled curriculum general objectives and specific objectives adequately covered the requirements for use of statistics in research.

\subsection{Statistics Content in the Curriculum}

Apart from the general objectives and specific objectives, Wei (2001) indicates that the aim of training in statistics should also be to increase the trainee's abilities in their practice. This means content is of importance to increase these abilities. The study, therefore, sought to determine the specific content that had been set aside in the curriculum to meet the objectives stated. The study found out that the curriculum with highest number of statistical courses had 4 courses. All the curriculums had 2 core courses in statistics and in one case one curriculum had 2 optional courses. The study determined that the scheduled content for the core courses covered descriptive and inferential statistics. The optional courses, for the curriculums that had them, provided an opportunity for advanced statistics techniques. Extracts from the sampled curriculums are as shown below.

\section{Curriculum Extract}

Research Methods: “The Design and application of quantitative and qualitative research strategies, Secondary data; Sampling methods; data collection; Data analysis; interpretation and presentation techniques." 
Statistics: Statistical principles as they relate to research, quantitative and qualitative data, parametric and nonparametric tests, statistical errors, research hypothesis, demographic projections; Analysis of variance; rationale and terms; Multiple comparisons, two-way analysis; Factor analysis and other multivariate techniques.

Decision Analysis: Structural decisions I; alternatives, consequences, objectives and uncertainties, structural decisions II; Objectives, hierarchies, and decision trees: Decision analysis software; multi objective value analysis; sensitivity analysis; probability analysis; subjective probability; modeling risk attitude; Theoretical probability distributions.

Operations Research: Formulation of Linear Optimization Models; Algebraic and Geometric representations of Linear Optimization Models; simplex method of solution; Introduction to optimization Models; Dynamic optimization of inventory scheduling; Decision making over unbounded horizon; Optimization methods for an unbound horizon; Optimization with a non-linear objective function; Probabilistic dynamic programming models; waiting the model; computer simulation of management; implementation of operations research.

Based on the study findings it was noted that the sampled curriculums met some of the needs of statistics training as stated by different scholars discussed below. Wei (2001) noted that training curriculum should contain survey designing, data collecting, describing, analyzing and explaining. All this aspects were noted by the study to have been included in the sampled curriculums. Bishop and Talbot (2001) note that attention should be devoted to strategic issues in statistics such as what technique is most appropriate and how to organize data collection. This requirement by Bishop and Talbot (2001) was found not adequately covered in the sampled curriculums. The sampled curriculums had general concepts about this aspect but were not specific to determining the best statistic and how to organize data. This makes implementation of the curriculum very general and may or may not cover the need of determining best statistic to use. The benchmark curriculum has very specific expectations on this. It expects students to be able to make an informed decision on how to select a good research question, how to select cases, how to measure and collect data, and what methods to choose for the analysis in their own prospective research. This was determined as a non conformity of the sampled curriculums. Recommendations by McDonald (2001) that university courses on quantitative research should have sections on official statistics, and the pros and cons of micro data, dealing with missing values and non response, appropriate use of weights and analysis of complex sample design were also determined to be inadequately covered. Despite the inadequacies that need to be improved, the study notes that the sampled curriculums content covers the statistical knowledge needs to enable use of statistics in research.

\subsection{Information Communication Technology Content}

The study in section 4.4 determined that ICT is a need for one to use statistics in research. The findings were in agreement with Jung (2005) who notes that structure and content of training in this contemporary society that relies on ICT should always have elements of ICT. The study sought to determine if ICT concepts are adequately catered for in the sampled masters' curriculums. The study determined that ICT concepts were included in three courses which were Statistics, Decision analysis and Operations research. The ICT concepts in each of the three courses were not related to each other. Every course was concerned about a different ICT concept. An extract from the sampled curriculum is as shown below.

\section{Curriculum Extract}

Statistics: Use of Statistical software (SYSTAT and SPSS).

Decision Analysis: Decision analysis software; multi objective value analysis; sensitivity analysis; probability analysis; subjective probability; modeling risk attitude;

Operations Research: Computer simulation of management;

The study findings show that the sampled curriculums have complied with sentiments by Starkings (1997) and Bishop and Talbot (2001). They noted that educational establishments need to be updating the curriculum to keep 
pace with changes in society and the work environment. The work environment in use of statistics as indicated by Jones (1997) and Friedman (2001) involves use of computer software for data analysis. Despite the sampled curriculums being compliant with scholars' requirements and the needs to use statistics, the way the ICT concepts were included is challenging to execute. The ICT concepts were included with other concepts making the courses too wide to be effectively learned in one semester of 4 months. At the same time the ICT concepts were treated as an addition to the courses which they were included.

The study notes that this inclusion method is an inferior way as compared to the bench mark curriculum which integrated ICT in every statistical concept covered. The benchmark curriculum advocates for use of statistical software at every stage of statistics and also recommends use of sets for data for this exercise. The way the sampled curriculums have treated ICT concepts leaves room for the implementers of the curriculum to teach ICT as a separate concept from statistics. The benchmark curriculum also has additional requirements that make the research trainees cover through their own initiative some of the ICT concepts. Examples of the additional requirements include asking students to attend workshops on use of software for data analysis. This is an element that the sampled curriculums were missing making them less likely to achieve the set objectives. The study determined this adding on rather than integrating ICT concepts and statistics concepts to be a major setback of the sampled curriculums. The study, therefore, notes that the way the sampled curriculums had presented ICT concepts cannot adequately meet the ICT knowledge needs to use statistics in research.

\subsection{Curriculum Recommendation for Instruction Procedures and Evaluation}

The study established that the sampled curriculum content in some cases was adequate and in other cases inadequate as discussed in sections above. The study further sought to determine the recommendations made by the curriculum in relation to instruction process. The study established that lectures, class discussion and students presentations common across the sampled curriculums. Extracts from the sampled curriculums are as shown below.

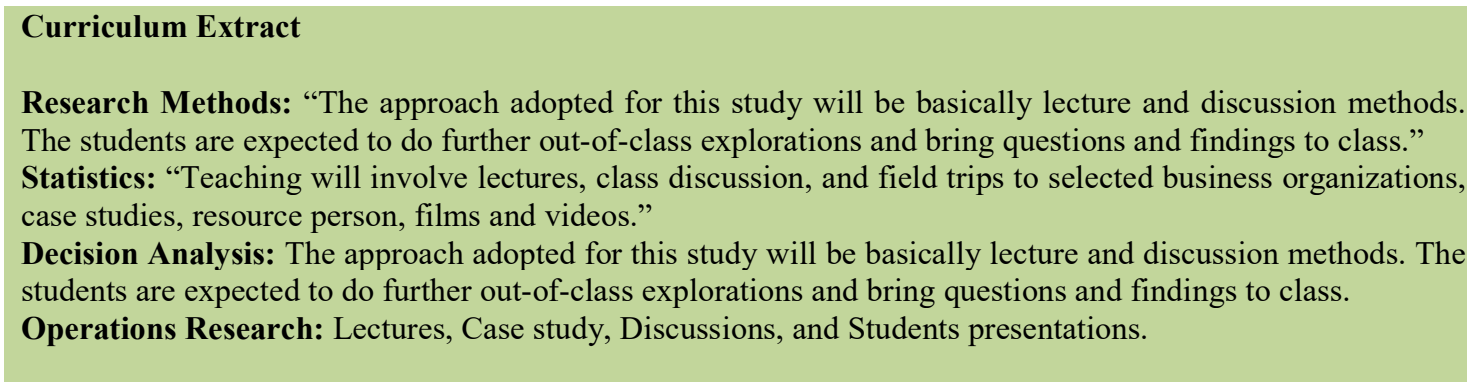

The study finding is similar to findings by Wei (2001) who indicated that training researchers in the use of statistics in China was through Class teaching and group discussion. However, Wei (2001) also notes that field training, $\mathrm{TV}$, broadcasting programs and Internet are also used. These methods were conspicuously missing in the sampled curriculums. Hirotsu (2001) recommends that training should be done in context. This recommendation by Hirotsu (2001) was not put into consideration by the sampled curriculums. The study looked at the sampled curriculum recommended instruction process against ideal standards set by the Wei and Hirostu and noted that the sampled curriculums had inadequacies. Additional inadequacies were noted when the sampled curriculums were measured against the benchmark curriculum. The benchmark curriculum recommended approaches were; lectures, tutorials, class discussion and presentations and workshops. The benchmark curriculum is superior because of the additional tutorials and workshop method. The study, therefore, notes that the recommended approaches for instruction in sampled curriculums are inadequate to meet the needs for use of statistics in research.

Myyry and Joutsenvirta (2015) noted that assessment methods are essential for students' learning experiences. The study, therefore, looked at the proposed evaluation procedures in the sampled curriculums. The study established that continuous assessment tests and end of semester sit in exam were the common form of exams administered. In addition in one case there were also term papers and practical in some courses. Extracts from the sampled curriculums are as shown below. 
Research Methods: Select and refine a researchable topic, then write 18 page typed double spaced proposal for a case field study, $(20 \%)$.

Present a final form, a research proposal including the findings, data analysis, summary, conclusion and recommendation. The paper should not exceed 20 paged typed double spaced, $(20 \%)$.

Final Exam (60\%).

Statistics: Continuous assessment tests and final examination.

Decision Analysis: Continuous Assessment Tests (CATs) and Assignments review of journals /Term Paper/ Practicals, $40 \%$.

End of Semester Examination $\quad, 60 \%$.

Operations Research: Student Assessment: Continuous assessment tests and final examination.

The study determined that emphasis is placed on end of semester examination with continuous assessments, projects and practical accounting to a maximum of $40 \%$. The study findings concur with Mukhwana et al (2016) who noted that at the post graduate level, coursework examination follows the same process as undergraduate programs. Mukhwana et al (2016) indicates that the students sit and write the exam at the end of the semester in which the course is taught. On passing the required coursework they proceed to next stage of research. The study noted shortcomings in the recommended evaluation procedures based on the discussion below.

Strijbos, and Sluijsmans (2010) note that summative evaluation is out of context, individualistic and is isolated from the learning process. Guligers et al. (2006) found that when the assessment form was perceived as authentic, the students were more prone to adopt deep learning strategies and there were also increases in generic skill achievement, such as problem-solving, analytic skills, and written communication skills. Myyry and Joutsenvirta (2015) noted that most of the students taking the open-book examination learned deeply and focused on understanding as compared to those taking class examinations. The study, therefore, noted that the recommended assessment procedures in sampled curriculum are not adequately encouraging mastery of skills. A comparison with the benchmark curriculum showed big variation in the way the learned knowledge and skills are assessed. The benchmark curriculum emphasized on open book assignments that were in context with how the knowledge will be applied. On the other hand the sampled curriculums emphasized on closed book end of semester exams that were out of context. The study identified assessment procedures as a major setback for understanding and using statistics in research.

\section{Conclusion and Recommendation}

The study sought to determine how masters' curriculum content meets the needs for students to use statistics in research. The study established that; general objectives and specific objectives in courses related to statistics adequately covered the requirements for statistics training; the scheduled content for the core courses covered descriptive and inferential statistics; ICT concepts are catered for in the sampled masters' curriculums, however, the courses are too wide to be effectively learned in one semester of 4 months; The study established that lectures, class discussion and students presentations are common methods of instruction across the sampled curriculums. The study established that continuous assessment tests and end of semester sit in exam were the common form of exams administered. In addition in one case there were also term papers and practical in some courses. However the end of semester exam carried more weight of $60 \%$.

It is important to note that it is at masters' level that the student for the first time is exposed to a thorough training in use of statistics in research. It's important that the curriculum is also thorough and without any loopholes for inadequate training. The study noted that the curriculum content was too wide to be covered in a single semester. This creates room for curriculum implementers to rush through in order to stay on schedule. The curriculum also did not integrate ICT in all statistical concepts but rather it was treated as a separate entity in courses that it was included. This creates a situation where not all lecturers training researchers will appropriately integrate ICT. The study notes that the proposed instructional methodologies are not adequate for training of researchers to use statistics. The proposed evaluation procedure is not adequate in assessing all the acquired skills especially the application aspects of the learned knowledge. This provides avenue for implementers who are not keen with training to drill students for examination and eventually miss out on important concepts. 
The study, therefore, proposes that ICT especially the use of statistical software be integrated in every concept being taught in statistics. Secondly the study recommends that for quantitative researchers, research inclusive of statistical courses be increased to a minimum of four and not less than two others to be optional. This will provide an opportunity for masters' students to be well trained in use of statistics in research. A certificate for quantitative research should be given to students who perform well in research and statistics in research courses. Such students are the ones who should be entrusted with teaching research in future and supervising post graduate students with a bias to use of statistics in research. Lastly the study recommends that examination for use of statistics in research should be open book examinations. The examinations should require the student to design a study with consideration of contemporary modes of data analysis, collect data using contemporary methods and tools, analyze data using contemporary software, interpret, test hypotheses and report findings using contemporary ways and write a report about the entire process he/she has one through with an intention of future improvement.

\section{References}

Assimakopoulos, D., \& Yan, J. (2006). Sources of knowledge acquisition for Chinese software engineers. $R \& D$ Management, 36(1), 97-106.

Bishop, G. \& Talbot, M. (2001). Statistical thinking for novice researchers in the biological sciences. Training researchers in the use of statistics, 215-226.

Clark R. B. (1993) The research Foundations of Graduate Education. Germany, Britain, France, United States, Japan. University of Caifornia press, Los Angeles.

Cloete, N., \& Maassen, P. (2015). Roles of universities and the African context. Knowledge production and contradictory functions in African higher education, 1-17.

Dempster, M., \& McCorry, N. K. (2009). The role of previous experience and attitudes toward statistics in statistics assessment outcomes among undergraduate psychology students. Journal of Statistics Education, 17(2).

Estabrooks, C. A., Rutakumwa, W., O’Leary, K. A., Profetto-McGrath, J., Milner, M., Levers, M. J., \& ScottFindlay, S. (2005). Sources of practice knowledge among nurses. Qualitative health research, 15(4), 460-476.

Friedman, J. H. (2001). The role of statistics in the data revolution?. International Statistical Review, 69(1), 5-10.

Glencross, M. J., \& Binyavanga, K. W. (1997). 25. The role of technology in statistics education: a view from a developing region. Research on the role of technology in teaching and learning statistics, 301.

Guligers JTM, Bastiaens TJ, Kirschner PA, et al. (2006) Relations between student perceptions of assessment authenticity, study approaches and learning outcome. Studies in Educational Evaluation 32(4): 381-400.

Harraway, J. Manly, B. Sutherland, H. \& McRae, A. (2001). Meeting the statistical needs of researchers in the biological and health sciences. Training researchers in the use of statistics, 177-195.

Hirotsu, C. (2001). Statistical training of researchers in total quality management: the Japanese experience. Training researchers in the use of statistics, 53-63.

Iversen, G. R. (2001). Bayesian Models and World Contructs. Training Researchers, 103.

Jones, P. (1997). Examining the Educational Potential of Computer-Based Technology in Statistics. Research on the Role of Technology in Teaching and Learning Statistics, 233.

Jung, I. (2005). ICT Pedagogy Integration in Teacher Training: Application Cases Worldwide, in Educational Technology and Society, volume 8 (2) pp 94-101.

McDonald, S. (2001). Practical and educational problems in sharing official microdata with researchers. Training researchers in the use of statistics, 119-128.

Mukhwana, E. Oure, S. Too J. and Some D. K. (2016): State of Postgraduate Research Training in Kenya. Commission for University Education. Discussion Paper 02. Nairobi, Kenya.

Murray, G. D. (1991). Statistical aspects of research methodology. British journal of surgery, 78(7), 777-781.

Musiige, G., \& Maassen, P. (2015). Faculty perceptions of the factors that influence research productivity at Makerere University. Knowledge production and contradictory functions in African higher education, 109-127. 
Myyry, L., \& Joutsenvirta, T. (2015). Open-book, open-web online examinations: Developing examination practices to support university students' learning and self-efficacy. Active Learning in Higher Education, 16(2), $119-132$

Oliver, R., \& Towers, S. (2000, December). Benchmarking ICT literacy in tertiary learning settings. In Learning to choose: Choosing to learn. Proceedings of the 17th Annual ASCILITE Conference (pp. 381-390).

Pearson, M and Brew, A (2002) Research Training and Supervision Development in journal of studies in higher education volume 27, No. 2, pp 135-150

Sabzwari, S. Samreen, K. and Khuwaja, A. K. (2009) Experiences, attitudes and barriers towards research amongst junior faculty of Pakistani medical universities in journal of BMC Medical Education.

Sawyerr, A. (2004) African Universities and the Challenge of Research Capacity Development in JHEA/RESA Vol. 2, No. 1, pp. 211-240

Scott (2015) Why Kenya ranks low on quality of academic research, retrieved from https://www.businessdailyafrica.com/lifestyle/society

Sprent, P. (2003). Statistics in medical research. Swiss medical weekly, 133(3940).

Starkings, S. (1997). How Technological Introduction Changes the Teaching of Statistics and Probability at the College Level. Research on the role of technology in teaching and learning statistics, 233-254.

Starkings, S. and Jerome H (2001) The Pre-requisite Knowledge Required by Students Starting Data Analysis Classes at University presented in International Statistical Institute, 53rd Session .

Strijbos, J. W., \& Sluijsmans, D. (2010). Unravelling peer assessment: Methodological, functional, and conceptual developments.

Svensson, E. (2001). Important considerations for optimal communication between statisticians and medical researchers in consulting, teaching and collaborative research-with a focus on the analysis of ordered categorical data. Training researchers in the use of statistics, 23-35.

Tijssen, R. (2015). Research output and international research cooperation in African flagship universities. Knowledge production and contradictory functions in African higher education, 61-74.

Votruba, C. J (1996) Strengthening the University's Alignment with Society: challenges and Strategies in Journal of Public Service and Outreach, Volume 1, pp 29-36

Wei, Y. (2001). The training of researchers in the use of statistics in China. Training researchers in the use of statistics, 311-317.

Yamamoto, S. (2001). Basic research and the role of universities in Japan: Workshop on basic research at Oslo, Norway, 29-30 October 2001. Retrieved from http://www.oecd.org/dataoecd/39/32/2674535.pdf

Zwiers, F. W., \& Von Storch, H. (2004). On the role of statistics in climate research. International Journal of Climatology, 24(6), 665-680. 